\title{
Subcutaneous dirofilariasis in Nova Scotia
}

\author{
DAVID JM HALDANE MB FRCPC, B LYNN JOHNSTON MD FRCPC, NOREEN MG WALSH MD FRCPC
}

DJM HALDANE, BL JOHNSTON, NMG WALSH. Subcutaneous dirofilariasis in Nova Scotia. Can J Infect Dis 1996;7(1):67-69. A case of dirofilariasis in a 78-year-old woman from Nova Scotia is described along with the histological findings and the basis of identification of the parasite. The patient developed a subcutaneous nodule, which was excised. Dirofilaria ursi and ursi-like nematodes are a rare cause of subcutaneous nodules. This is the first time dirofilariasis has been diagnosed in an adult in Atlantic Canada.

Key Words: Dirofilariasis, Histology, Subcutaneous nodules

\section{Dirofilariose sous-cutanée en Nouvelle-Écosse}

RÉSUMÉ : Un cas de dirofilariose chez une Néo-écossaise de 78 ans est décrit ici, accompagné d'observations étiologiques et d'une base d'identification de ce parasite. La patiente a développé un nodule sous-cutané qui a pu être excisé. Le Dirofilaria ursi et les nématodes de types ursi sont une rare cause de nodules sous-cutanés. Il s'agit du premier diagnostic de dirofilariose posé chez un adulte dans la région atlantique au Canada.

$\mathrm{D}$ irofilaria species cause a filarial infection in animals and occasionally accidental infection in humans. These infections are most commonly manifested by either subcutaneous or pulmonary nodules, depending on the species of dirofilaria involved. These nodules may cause anxiety about the possibility of malignancy, which can be resolved by histological examination. Many physicians are unaware of the occurrence and endemic nature of these parasites. Infections with Dirofilaria ursi have been reported from the northern United States, Canada and Japan (1). We report the first case of an adult Dirofilaria (Nochtiella) ursi (or ursi-like) infection acquired in Atlantic Canada.

\section{CASE PRESENTATION}

A 78-year-old woman from Nova Scotia was referred to the Infectious Disease Clinic for evaluation after a subcutaneous nodule had been excised from her left anterior chest wall. In
October 1994, six weeks before presentation, she had noticed an erythematous, warm and tender area below her left clavicle. In addition, she had been febrile, anorexic and had had left cervical adenopathy. Penicillin had been prescribed by her family doctor and, although the erythema had resolved, a cystic lesion had developed. Her family doctor described the lesion as resembling an infected sebaceous cyst.

Other medical conditions included hypercholesterolemia, hypertension, and iron and vitamin $\mathrm{B}_{12}$ deficiencies, for which she was undergoing treatment with lovastatin, diltiazem, iron and cyanocobalamin. She had travelled to Florida the previous winter and to Spain for 10 days in February 1992. She had spent some time with her family at a cottage on the Northumberland Strait that summer but had not been in any wooded areas, did not hike or camp and could not recall any insect bites. Her pet dog had died of old age at the time she developed this illness.

Department of Microbiology and Medicine; Department of Medicine, Division of Infectious Diseases; and Department of Pathology, Division of Anatomic Pathology, Victoria General Hospital and Dalhousie University, Halifax, Nova Scotia

Correspondence and reprints: Dr David JM Haldane, Department of Microbiology, Victoria General Hospital, 1278 Tower Road, Halifax, Nova Scotia B3H 2Y9. Telephone 902-428-2392, fax 902-428 4432

Received for publication April 25, 1995. Accepted July 5, 1995 


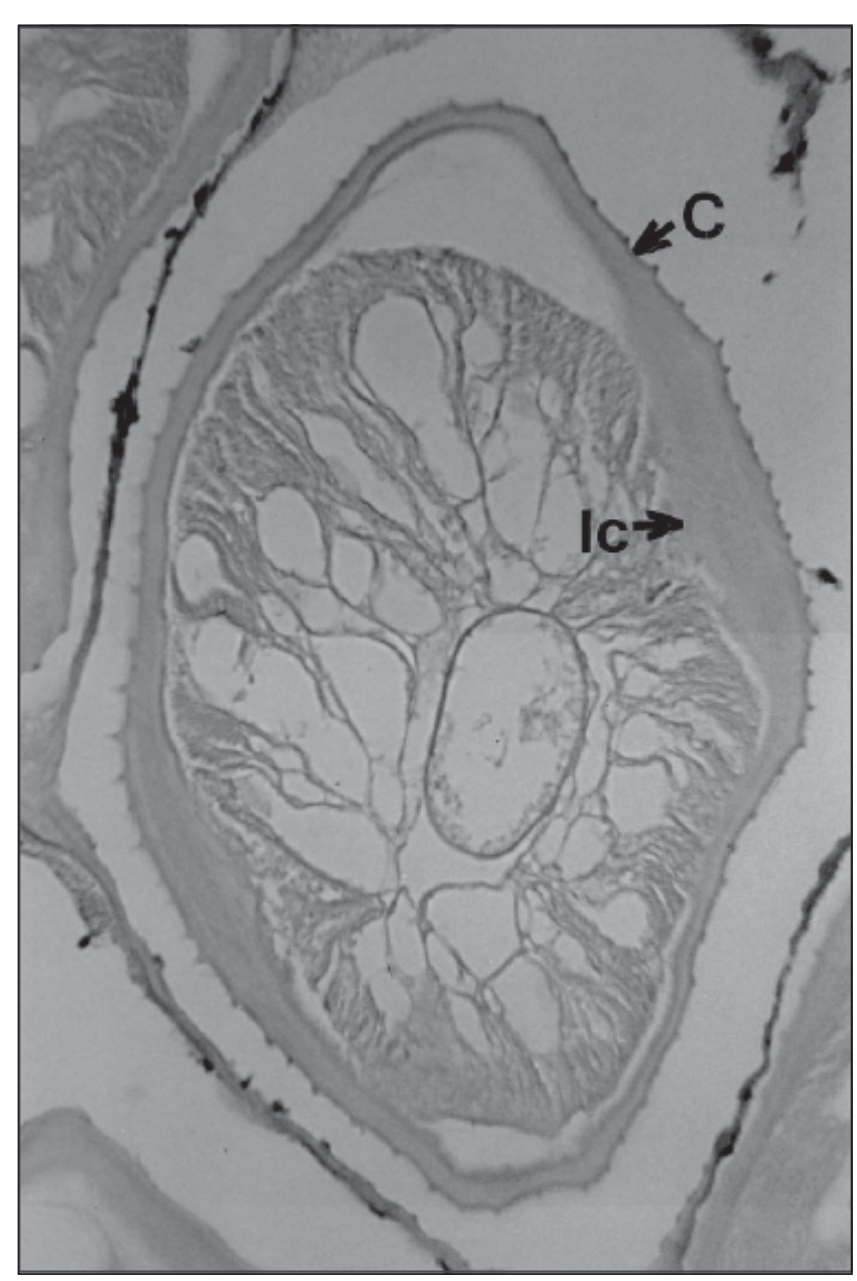

Figure 1) Hematoxylin and eosin stained section of Dirofilaria (Nochtiella) ursi-like isolate. C Cuticle; lc Lateral cord. x400

When she was seen in the Infectious Disease Clinic, there was a well healed incisional scar at the site of the excisional biopsy with no other abnormalities. Laboratory investigations at the time of her clinic visit revealed a normochromic, normocytic anemia with normal vitamin $\mathrm{B}_{12}$ and folate levels. Biochemical studies, immunoglobulin E levels and eosinophil counts were all normal.

The biopsy specimen (Figure 1) consisted of an elongated portion of fibro-fatty tissue in the centre of which was an inflammatory nodule. Within the core of the nodule there was a nematode parasite surrounded by suppurative and granulomatous inflammation. Peripheral to this was an inflammatory scarring reaction laden with lymphohistocytic cells and numerous eosinophils. The diameter of the parasite was up to $194 \mu \mathrm{m}$ in longitudinal sections and had a maximum diameter of $256 \mu \mathrm{m}$ on cross-section. The least laterally compressed cross-section measured $170 \times 190 \mu \mathrm{m}$. The cuticle was 5 to $9 \mu \mathrm{m}$ thick and was made up of three layers. The outer layer had ridges that were 1 to $2 \mu \mathrm{m}$ high and approximately $2 \mu \mathrm{m}$ in diameter. The distance between the ridges was 6 to $9 \mu \mathrm{m}$. There were approximately 65 to 75 ridges in the total circumference of the nematode. The fibres of the outer layers could be seen to be orientated in different directions in some sections, and the inner layer was attached to the muscle tissue. There was thickening of the cuticle at the lateral cord, but no lateral cord nuclei were visible. The intestine and sex organ of the parasite were present centrally. Based on morphology, the organism was identified as a presumptive D ursi or related species.

\section{DISCUSSION}

There are two subgenera of the genus dirofilaria: dirofilaria (type species Dirofilaria immitis, the dog heartworm) and nochtiella (type species Dirofilaria repens), which includes D ursi and related species. In the natural life cycle of D ursi, the bear is the definitive host (in eastern Canada: Ursus americanus, the black bear), and the adult nematode is found most commonly in the paratracheal and perirenal tissues. The infected host develops microfilaremia, and larvae can be ingested by a blackfly during its blood meal. The ingested larvae undergo further development and reach infectivity in nine days at $23^{\circ} \mathrm{C}$. When another bear is subsequently bitten by the blackfly, the bear becomes infected, the larvae mature to the adult form, and the bear develops microfilaremia seven to nine months later (1). Humans act as an accidental host and the development of microfilaremia has not, to our knowledge, been reported with D ursi infection, although Green (2) reported a patient on long term steroid therapy for systemic lupus erythematosis who developed a microfilaremia that was most likely from a dirofilarial infection. A related species is Dirofilaria subdermata for which the definitive host is the porcupine, in which the adult is found in subcutaneous tissues (3). This organism cannot be distinguished easily from D ursi on tissue specimens and this identification cannot be definitively excluded for the isolate described herein.

The nochtiella subgenus is associated with subcutaneous dirofilariasis, in contrast to the dirofilaria subgenus, which is primarily associated with pulmonary dirofilariasis. Other species in this group that are associated with subcutaneous dirofilariasis include Dirofilaria tenuis, whose natural definitive host is the raccoon and has been reported from the southeastern United States, and D repens, whose natural definitive hosts are dogs and cats in Europe, Asia and Africa. D ursi and ursi-like isolates have been identified in patients who acquired their infections in the northern United States and central/western Canada. However, the same organism has also been found in bears in New Brunswick. A survey from Northumberland County in New Brunswick demonstrated D ursi infection in 37 of $110(33.7 \%)$ bears tested (4).

Our identification (presumptive D ursi or ursi-like) was based on characteristics described in the literature (5). The diameter of this isolate was slightly greater than that described by Gutierrez (5) as determined by the maximal measurements of cross-sections. The diameter, however, was less than 200 $\mu \mathrm{m}$ in longitudinal sections and in the most symmetrical cross-section the measurements were $170 \times 190 \mu \mathrm{m}$. We suggest that the maximal cross-sectional measurements were increased as a result of oblique cuts through the body and lateral compression of the worm. Other considerations included $\mathrm{D}$ repens because of the history of travel to Spain, and 
$\mathrm{D}$ tenuis because of the trip to Florida. We excluded $\mathrm{D}$ repens because the majority of isolates have been larger (between 220 and $660 \mu \mathrm{m}$ ) with a greater number of longitudinal ridges (approximately 95 to 105). In addition, the degree of potential exposure was small, consisting only of the period of the patient's travel. Although survival of up to eight years has been reported, the usual lifespan of $D$ repens in tissues is only two to three years (6). D tenuis was excluded on the basis of the diameter of the nematode and the morphology of the longitudinal ridges (which are typically 280 to $330 \mu \mathrm{m}$ with longitudinal ridges that are narrowly spaced, low and rounded), in addition to the short period of potential exposure (5).

Infection by dirofilaria is frequently asymptomatic until the parasite dies, when an inflammatory reaction occurs and a nodule containing the worm develops. In the present case the worm was not viable when excised, but its condition suggested that death had occurred recently and may have triggered the onset of the symptoms that caused presentation. The clinical presentation of D ursi-like infections was recently reviewed by Beaver et al (3). Of the 10 patients he listed all were adult females and had infection of the upper trunk, head or arm near the axilla. They presented with one or more nodules that were reported to be tender in four of eight cases where the information was provided. Our patient had a typical presentation. Whether the sex distribution is related to a predisposition to the development of this infection, to the behaviour of the blackfly vector, or to more careful self-examination for detection of nodules, is unknown. The anatomical distribution is most likely related to those areas exposed to blackfly bites. We suspect that the present patient became infected in the spring of 1994, five months before presentation. Blood for microfilaremia was not examined because the diagnosis was not made before excision of the worm. Excision of the nodule was curative, as is usually the case, and four months later the patient was well.

The cases reviewed by Beaver et al (3) were distributed from Vermont to British Columbia. The only previous report of a suspected dirofilarial infection in Atlantic Canada was that of a four-year-old boy who developed forehead and scalp nodules. On histological examination these were shown to contain an immature filaria identified as a Dirofilaria species (7). Our report supports the view that this unusual arthropodborne zoonosis occurs in Atlantic Canada and that it should be included as an unusual cause of subcutaneous nodules.

\section{REFERENCES}

1. Beaver PC, Jung RC, Cupp EW. Clinical Parasitology, 9th edn. Philadelphia: Lea and Febiger, 1984:387-92.

2. MacDougall LT, Magoon CC, Fritsche TR. Dirofilaria repens manifesting as a breast nodule, diagnostic problems and epidemiologic considerations. Am J Clin Pathol 1992;97:625-30.

3. Beaver PC, Wolfson JS, Waldron MA, Swartz MN, Evans GE, Adler J. Dirofilaria ursi-like parasites acquired by humans in the northern United States and Canada: report of two cases and brief review. Am J Trop Med Hyg 1987;37:357-62.

4. Duffy MS, Greaves TA, Burt MDB. Helminths of the black bear Ursus americanus in New Brunswick. J Parasitol 1994;80:478-80.

5. Gutierrez Y. Diagnostic features of zoonotic filariae in tissue sections. Hum Pathol 1984;15:514-25.

6. Settnes OP, Engebjerg E. Human subcutaneous dirofilariasis caused by Dirofilaria repens. Report of a case in Norway and review of recent literature. APMIS 1991;99:364-70.

7. Kahn ZA, Meerovitch E. Zoonotic filarial infection in a four year old child in Eastern Canada. Am J Trop Med Hyg 1968;17:730-2. 


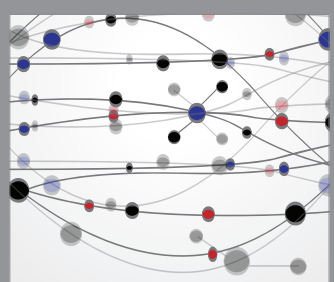

The Scientific World Journal
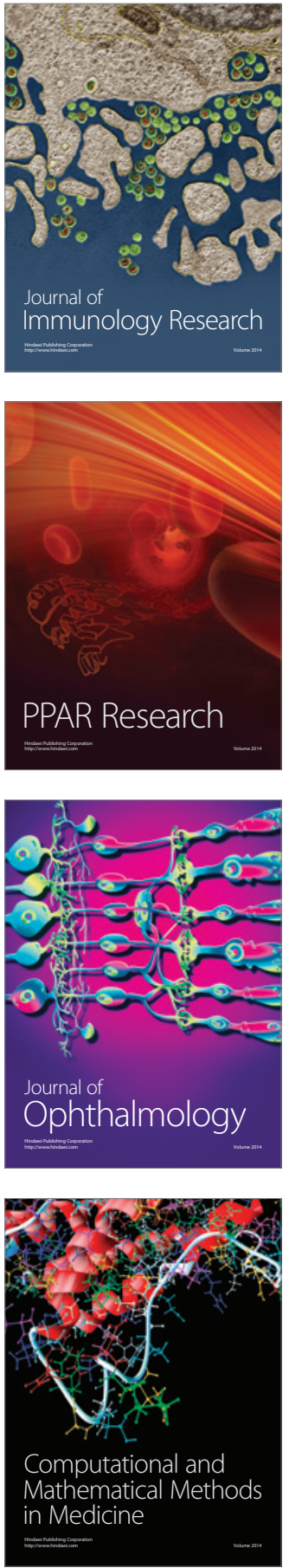

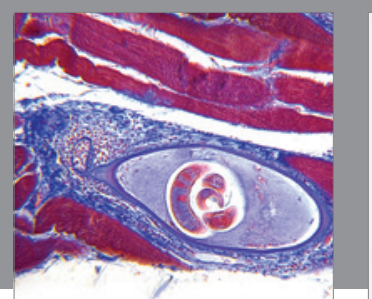

Gastroenterology Research and Practice

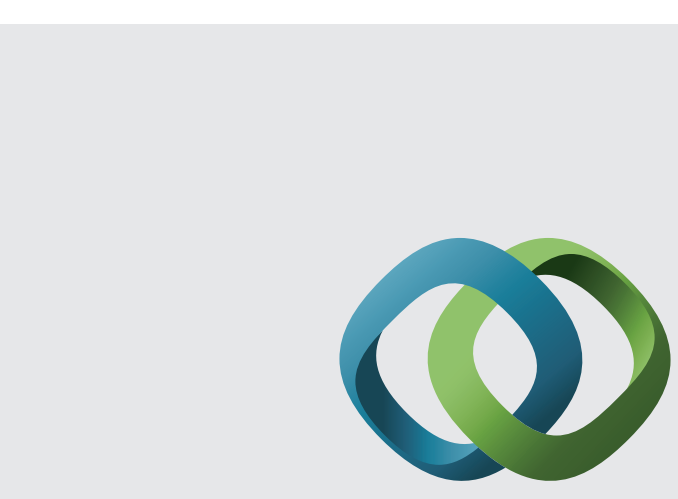

\section{Hindawi}

Submit your manuscripts at

http://www.hindawi.com
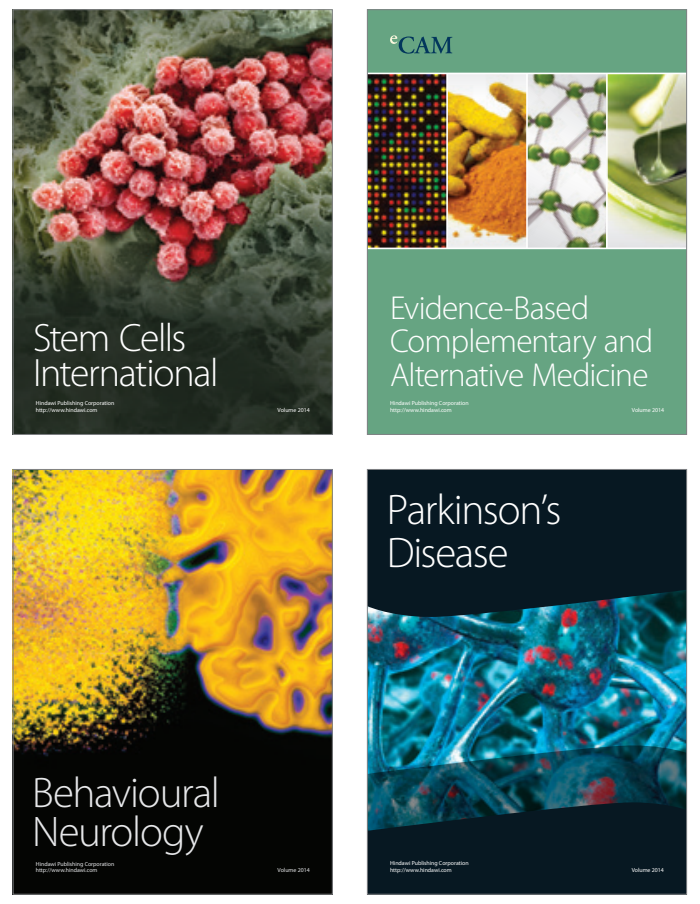
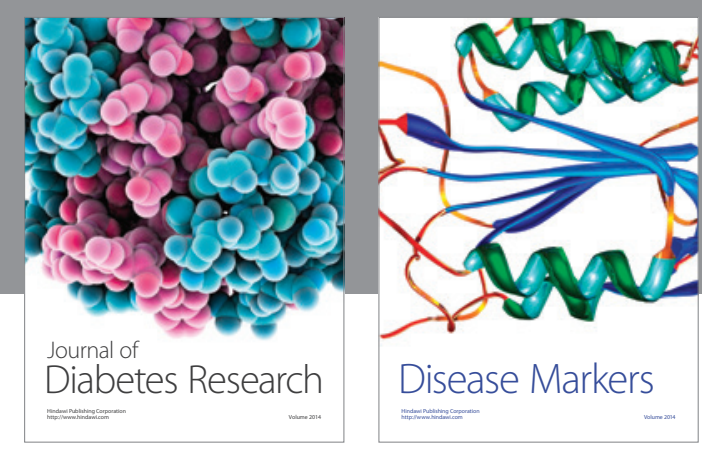

Disease Markers
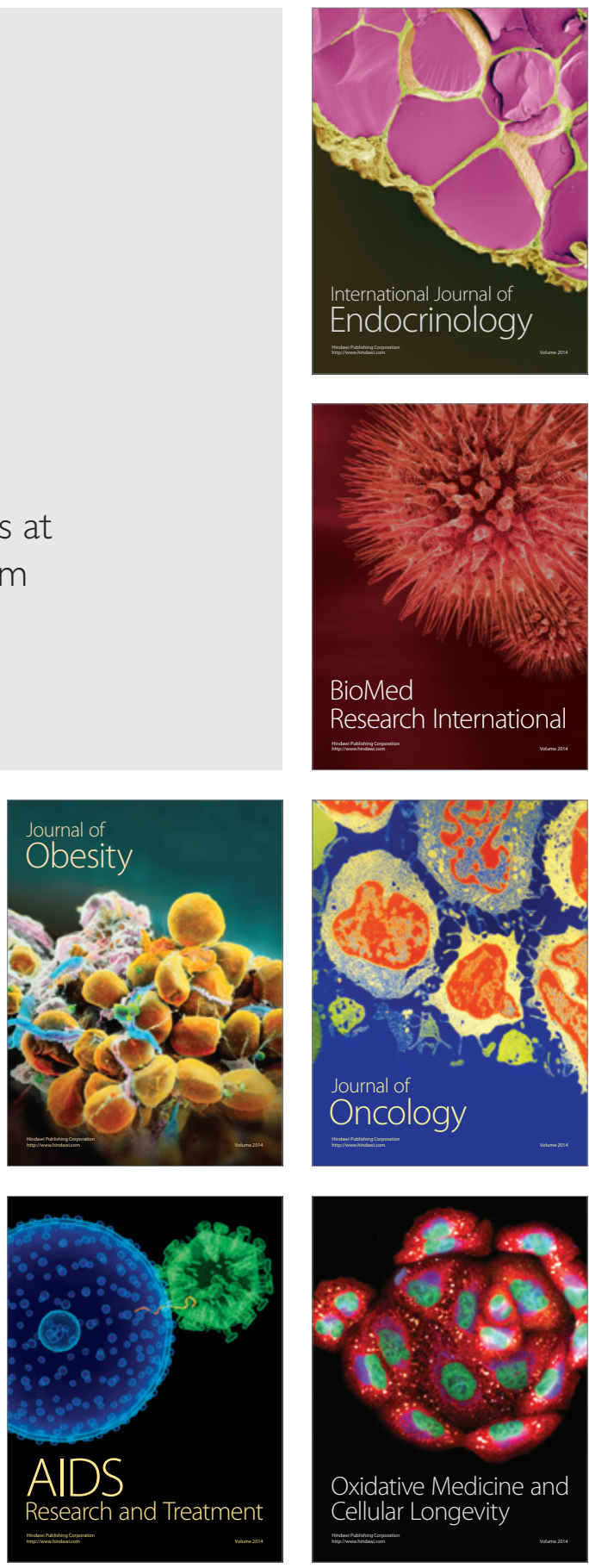